\title{
Modelo multicritério para avaliação e classificação da gestão organizacional: proposta e caso de uso
}

\author{
Helder Gomes Costa ${ }^{a *}$, Gisele Alvim de Rezende Vilas Boas ${ }^{b}$, \\ André Luís Policani Freitas ${ }^{c}$, Carlos Francisco Simões Gomes ${ }^{\mathrm{d}}$ \\ a*hgc@vm.uff.br, UFF, Brasil \\ bgisele.vboas@gmail.com, UFF, Brasil \\ cpolicani@uenf.br, UENF, Brasil \\ dcfsimoes@fgvmail.br, UFF, Brasil
}

\section{Resumo}

Este trabalho tem por objetivo apresentar um modelo multicritério de autoavaliação para a obtenção da classificação do desempenho organizacional à luz das práticas de excelência em gestão. 0 modelo multicritério proposto se baseia na aplicação do método ELECTRE TRI na obtenção de graus de credibilidade e classificações do desempenho organizacional. Foi efetuada uma aplicação com o objetivo de experimentar a aplicação do modelo proposto. Nessa aplicação, as escalas de avaliação basearam-se em likert (1932) e os critérios adotados foram inspirados nos seguintes prêmios de excelência em gestão: Prêmio Deming, Malcolm Baldrige, Europeu e PNQ. Como resultado foi possível obter a classificação e, também, identificar os critérios de excelência a serem priorizados, para a elevação da classificação alcançada pela organização.

Palavras-chave

Qualidade total. Multicritério. Prêmios de excelência. Decisão. ELECTRE TRI.

\section{Introdução}

Em ambiente de competição crescente, faz-se necessária a adoção de mecanismos para avaliação e posicionamento das práticas organizacionais. Segundo Vilas Boas e Costa (2013), uma das vertentes nesse contexto é proveniente da Total Quality Management (TQM), que se tornou mais evidenciada a partir da difusão dos prêmios de qualidade ou prêmios de excelência em gestão. Sharma e Talwar (2007) registram que em 2006 havia mais de 90 prêmios de qualidade ou excelência em negócios distribuídos em 75 países. Para Sharma e Talwar (2007) e Talwar (2009, 2011), os seguintes prêmios têm se consolidado como referências mundiais na busca da excelência organizacional: Deming Prize (DP), implantado no Japão, Malcolm Baldrige National Qualitiy Award (MB), implantado nos Estados Unidos, e EFQM Excellence Award (EFQMEA), implantado na Europa.

Em seus mecanismos de agregação, esses prêmios adotam a soma de pontos para obter o posicionamento e a classificação da organização. Esse procedimento de cálculo é fundamentado em uma lógica compensatória que pode mascarar os resultados. Por exemplo: um desempenho muito ruim em um critério pode ser compensado por um desempenho muito bom em outro critério, gerando a falsa impressão de que a organização tem um desempenho bom à luz de todo o conjunto de critérios considerados.

Outro aspecto a ser considerado é que o conjunto de critérios e os pesos a eles atribuídos são valores de referência para o setor produtivo como um todo, devendo ser validados ou até mesmo alterados quando utilizados para a gestão de uma organização em particular, incorporando aspectos associados aos seus valores, sua missão e ao seu posicionamento estratégico. Esse problema foi tratado por Vilas Boas e Costa (2013), que propuseram um modelo de autoavaliação pautado em um conjunto de critérios baseados nos principais prêmios internacionais, no prêmio da Fundação Nacional da Qualidade (FNQ) e 
na particularização dos pesos atribuídos aos critérios para o caso específico de uma organização.

A despeito dos avanços alcançados por Vilas Boas e Costa (2013), a questão referente ao emprego de algoritmos não compensatórios de agregação para a obtenção de uma classificação do desempenho da organização à luz das práticas de excelência em gestão ainda persistem.

Assim, o desafio que se impôs a essa pesquisa foi a construção de um modelo para avaliação e classificação da excelência organizacional baseado em uma abordagem híbrida de modelos reconhecidos que contorne a questão da lógica compensatória dos modelos usuais e, ao mesmo tempo, leve em conta as particularidades da organização quando da valoração da importância dos critérios.

0 presente trabalho se propõe a estender o trabalho de Vilas Boas e Costa (2013), apresentando um modelo multicritério baseado em método de lógica não compensatória para a classificação de uma organização quanto ao seu desempenho à luz das práticas de gestão propaladas nos prêmios de excelência em gestão e com importância valorada para a organização em particular.

Para atingir esse objetivo aplica-se o método ELECTRE TRI - Mousseau, Slowinski e Zielniewicz (1999) - ao conjunto de critérios e aos dados coletados por Vilas Boas e Costa (2013), obtendo-se a classificação da organização à luz das práticas de excelência em gestão. Após a classificação, uma análise de sensibilidade é aplicada aos dados coletados, explorando eventuais variações nas classificações alcançadas pela organização. É importante registrar que não se trata de um problema de avaliação de alternativas para escolha, mas sim da avaliação objetivando a classificação de uma organização.

Além dessa seção, o artigo contém outras quatro. A seção 2 apresenta uma breve descrição do método ELECTRE TRI. A seção 3 apresenta a síntese do domínio de conteúdo dos prêmios abordados, ou seja, fundamentos, critérios e características. $\mathrm{Na}$ seção 4 é descrito um caso de aplicação da proposta. Finalmente, a seção 5 traz as conclusões e a seção 6 apresenta a lista de referências.

\section{Sobre o ELECTRE TRI}

Segundo clássicos como Arrow (1963), Fishburn (1973), Saaty (1980), Changkong e Haimes (1983), Zeleny (1982) e Roy e Boyssou (1985), a tomada de decisão em um ambiente complexo envolve a consideração de múltiplos critérios. Vincke (1989) classifica as abordagens de auxílio multicritério à decisão (AMD) em: de critério único de síntese; interativas local; e de subordinação.
Conforme descrito em Costa et al. (2007), os métodos baseados em critério único de síntese caracterizam-se por buscar uma função que agregue diferentes funções de utilidade em uma função única. Observa-se que o termo utilidade é utilizado como similar do termo valor. A razão da escolha do termo utilidade baseia-se no fato de que ele é um termo clássico e de uso corrente na área do artigo, tendo sua origem nos trabalhos de Carl Menger e de Vilfredo Pareto, além de estar associado à Teoria da Utilidade Multiatributo (Multi-Attribute Utility Theory, MAUT), amplamente referenciada no âmbito do AMD. Dentre os métodos e teorias que se baseiam em critério único de síntese destacam-se: o AHP (SAATY, 1980), a Teoria da Escolha Social (ARROW, 1963) e a MAUT, apresentada por Fishburn (1970) e consolidada em Keeney e Raiffa (1976).

Antunes et al. (1989) e Antunes e Clímaco (1992) relatam que as abordagens interativas alternam fases de cálculo e fases de decisão, com o analista de decisão interagindo com o modelo. Esse tipo de abordagem é particularmente importante quando se busca uma solução única que seja ótima ou que esteja próxima do ponto ótimo.

Para Costa et al. (2007), no âmbito dos Métodos de Subordinação - também denotados por Métodos de Sobreclassificação - um conjunto finito de alternativas/ ações $(A)$ são valoradas sob uma família/vetor de critérios $(F)$, construindo-se relações de subordinação não compensatórias entre as alternativas. Essa relação não compensatória caracteriza-se pela não criação de uma função única que agregue os desempenhos alcançados, considerando todos os critérios. Essa função única agregadora é modelada na Escola Americana ou de Critério Único de Síntese. Buscando estabelecer uma ilustração didática desse conceito, Costa (2005) e Costa et al. (2007) valem-se de um exemplo didático baseado no voleibol para ilustrar esse conceito. A seguir, apresenta-se uma revisão desse exemplo:

Para se estabelecer bem a diferença entre os métodos de agregação em uma função única de valor e os métodos de sobreclassificação, pode-se fazer uma analogia com o que acontece em uma partida de voleibol no confronto entre os times $A$ e B. Se, no primeiro set, A ganha de B por 25 a 20, duas análises podem ser feitas:

- Usar uma função agregadora aditiva (soma de pontos) para obter o resultado final. Nesse caso A seria o vencedor da partida por 85 a 75 ;

- Usar o número de sets para definir o vencedor. Nesse caso, B seria o vencedor por 3 a 1. Cada set tem peso um e o vencedor do set recebe essa pontuação, independente do valor dos pontos do set. A pontuação obtida em um set não é compensada pela pontuação obtida em outro set. 
0 princípio fundamental dos métodos de sobreclassificação pode ser considerado semelhante a essa segunda abordagem se considerarmos que cada set equivale a um dos critérios da análise multicritério.

Os métodos de sobreclassificação têm sua origem na família ELECTRE - uma outra família de métodos de subordinação bem conhecida é a família Promethee, originada em Brans, Mareschal e Vincke (1984). A família ELECTRE é composta, atualmente, pelos seguintes métodos: ELECTRE 1 (ROY, 1968), ELECTRE 11 (ROY; BERTIER, 1971), ELECTRE 111 (ROY, 1978), ELECTRE IV (ROY; HUGONNARD, 1981), ELECTRE IS (ROY; SKALKA, 1985), ELECTRE TRI (MOUSSEAU; SLOWINSKI; ZIELNIEWICZ, 1999; YU, 1992) e ELECTRE TRI-C (FIGUEIRA et al., 2011). A seguir apresenta-se um resumo sobre a finalidade de cada um desses métodos:

- Métodos ELECTRE 1 e 1S. Particionam o conjunto de alternativas viáveis em dois subconjuntos: subconjunto não dominado e subconjunto dominado. Esses métodos são utilizados em problemas de escolha de alternativas, sendo particularmente interessantes para a escolha de uma "cesta de alternativas" e não necessariamente para a escolha de uma alternativa única.

- Métodos ELECTRE 11, 111 e IV. Esses métodos ordenam as alternativas presentes no conjunto de alternativas viáveis. Conforme reportado em Costa et al. (2007), o método ELECTRE 11 usa o conceito de critério verdadeiro para estabelecer as relações de subordinação, porém usa uma estrutura de relaxamento para obter a ordenação das alternativas. Os métodos ELECTRE III e IV utilizam o conceito de pseudocritério para estabelecer uma relação de credibilidade a partir do qual ordenam as alternativas através de um processo de "destilação". Em algumas situações utiliza-se a ordenação para fazer escolhas, o que deve ser efetuado com cautela, devido a eventuais problemas de reversão de ordem.

- Método ELECTRE TRI. 0 método ELECTRE TRI busca resolver problemas de classificação ordenada nos quais classificam-se alternativas em classes que mantêm uma relação de ordem entre si; ou seja: dado um conjunto de $A=\left[A_{1}, A_{2}, \ldots, A_{n}\right]$ alternativas, o ELECTRE TRI associa-as a um conjunto de $k$-classes ordenadas $\mathrm{C}=\left[\mathrm{C}_{1}, \mathrm{C}_{2}, \ldots, \mathrm{C}_{k}\right]$. O ELECTRE TRI-C é uma variante do ELECTRE TRI que opera com um valor central de referência para o estabelecimento da classificação.

Assim, o método de multicritério mais indicado para o tipo de problema abordado no presente trabalho (categorização e classes ordenadas) é o método ELECTRE TRI. A título de ilustração, objetivando fornecer ao leitor uma visão de aplicações desenvolvidas no Brasil envolvendo a aplicação do ELECTRE a problemas de classificação ordenada, citam-se: Miranda e Almeida (2003), Costa e Herrera (2003), Costa, Soares e Oliveira (2004a, b), Szajubok, Alencar e Almeida (2006), Szajubok, Mota e Almeida (2006), Neves e Costa (2006), Alencar, Almeida e Mota (2007), Costa et al. (2007) e Freitas, Rodrigues e Costa (2009).

A Figura 1, obtida de Costa et al. (2007), ilustra um conjunto formado por $\mathrm{h}+1$ classes, delimitadas por $\mathrm{h}$ limites de classe, considerando um conjunto de critérios $F=\left[g_{1}, g_{2}, \ldots, g_{m}\right]$. Uma classe genérica $C_{h}$ é delimitada por um limite inferior $b_{h}$ e um limite superior $\mathrm{b}_{\mathrm{h}}-1$.

No ELECTRE TRI, a classificação é obtida a partir da construção e exploração de uma relação de subordinação $\mathrm{aSb}_{\mathrm{h}}$, que é lida como "a sobreclassifica $b_{h}$ " e significa que "a não tem um desempenho pior do que o limite $b_{h}$ " (Figura 1). Na validação de $\mathrm{aSb}_{\mathrm{h}}$ devem-se verificar duas condições:

- Concordância: para que $\mathrm{aSb}_{\mathrm{h}}$ seja aceita, uma maioria suficiente de critérios deve ser a favor dessa afirmação.

- Não discordância: em nenhum critério deve ocorrer uma rejeição intensa à afirmação $\mathrm{aSb}_{\mathrm{h}}$. Para a obtenção de $\mathrm{aSb}_{h}$, calcula-se:

- o índice de concordância c $\left(a, b_{h}\right)$

$c\left(a, b_{h}\right)=\sum \mathrm{w}_{\mathrm{j}} \cdot c j\left(a, b_{h}\right) / \sum w_{j}$

$$
\text { onde }\left\{\begin{array}{l}
c_{j}\left(a, b_{h}\right)=0 \text { se } g_{j}\left(b_{h}\right)-g_{j}(a) \geq p_{j}\left(b_{h}\right) \\
c_{j}\left(a, b_{h}\right)=1 \text { se } g_{j}\left(b_{h}\right)-g_{j}(a) \leq q_{j}\left(b_{h}\right) \\
\text { caso contrário: } c_{j}\left(a, b_{h}\right)=\frac{\left(p_{j}\left(b_{h}\right)+g_{j}(a)-g_{j}\left(b_{h}\right)\right)}{\left(p_{j}\left(b_{h}\right)-q_{j}\left(b_{h}\right)\right)}
\end{array}\right.
$$

- o índice de discordância parcial $d_{j}\left(a, b_{h}\right)$

$\left\{\begin{array}{l}d_{j}\left(\mathrm{a}, b_{h}\right)=0 \quad \text { se } g_{j}(a) \leq g_{j}\left(b_{h}\right)+p_{j}\left(b_{h}\right) \\ d_{j}\left(\mathrm{a}, b_{h}\right)=1 \quad \text { se } g_{j}(a)>g_{j}\left(b_{h}\right)+v_{j}\left(b_{h}\right) \\ \text { caso contrário: } d_{j}\left(a, b_{h}\right)=\frac{g_{j}\left(b_{h}\right)-g_{j}(a)-p_{j}\left(g_{j}\left(b_{h}\right)\right)}{v_{j}\left(g_{j}\left(b_{h}\right)\right)-p_{j}\left(g_{j}\left(b_{h}\right)\right)}\end{array}\right.$

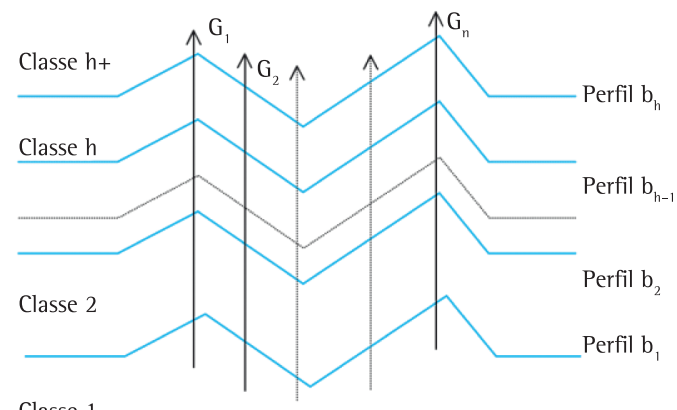

Classe 1

Figura 1. Classes de referência no ELECTRE TRl. Fonte: Costa et al. (2007). 
- $o$ índice de credibilidade $\sigma\left(a, b_{h}\right)$

$$
\sigma\left(a, b_{h}\right)=c\left(a, b_{h}\right) \prod_{j \in \bar{F}} \frac{1-d_{j}\left(a, b_{h}\right)}{1-c_{j}\left(a, b_{h}\right)}
$$

onde, $\mathrm{F}=\left\{j: d_{j}\left(a, b_{h}\right)>c_{j}\left(a, b_{h}\right)\right\}$

Na Equação 3 é possível observar que quando não há discordância em nenhum critério, o índice de credibilidade $\sigma\left(\mathrm{a}, \mathrm{b}_{\mathrm{h}}\right)$ é igual ao índice de concordância global $c\left(a, b_{h}\right)$. Assim, quando não é considerado o veto, tem-se $\sigma\left(a, b_{h}\right)=c\left(a, b_{h}\right)$.

\section{Sobre os prêmios de excelência em gestão}

Nesta seção são descritas as principais características e conceitos dos principais prêmios de excelência em gestão internacionais e do Brasil. A motivação para apresentar essa descrição é o fato de os critérios desses prêmios serem a base utilizada na construção dos critérios para o modelo de autoavaliação desenvolvido na pesquisa.

0 Prêmio Deming (Deming Prize, DP) foi instituído no Japão na década de 1950 pela Union of Japanese Scientists and Engineers (JUSE). Conforme reportado em Ghobadian e Woo (1996), inicialmente esse prêmio objetivava propagar os fundamentos da qualidade através do reconhecimento de que as melhorias no desempenho surgem a partir de uma implementação bem sucedida de um sistema de controle da qualidade total (Total Quality Control) ou TQC. Segundo Cauchick Miguel (2001), os prêmios patrocinados pela JUSE são concedidos em cinco categorias, sendo que a categoria Deming Application Prize é a que recebe maior publicidade.

NIST (NATIONAL..., 2010) relata que o Prêmio Malcolm Baldrige (MB) foi estabelecido em 1987, seguido da criação, em 1988, da Foundation for the Malcolm Baldrige National Quality Award, encarregada de promover e administrar a premiação. Segundo Talwar (2009), esse prêmio se pauta em: identificar os requisitos para a excelência; facilitar a comunicação e o compartilhamento das melhores práticas de gestão entre organizações americanas; e, orientar o planejamento organizacional e oportunidades de aprendizagem. Bohoris (1995, p. 41) complementa que como o prêmio foi instituído "[...] sob um clima de concorrência industrial intensa, a sua abordagem enfatiza a satisfação do cliente para alcançar a competitividade".

Conforme descrito em EFQM (EUROPEAN..., 2008) e em Yousefie, Mohammadi e Monfared (2011), o prêmio europeu de qualidade da European Foundation for Quality Management (EFQM), atualmente conhecido como EFQM Excellence Award (EFQMEA), surgiu em 1992, em continuidade à criação do modelo de excelência da EFQM, em 1991. Para Tavana et al. (2011), esse prêmio foi inicialmente desenvolvido para melhorar a posição competitiva das empresas da Europa Ocidental no mercado mundial, acelerando a aceitação da qualidade como estratégia competitiva. Conforme destacam Bohoris (1995), Sharma e Talwar (2007), Mavroidis, Toliopoulou e Agoritsas (2007) e Shahroudi e Kohan (2011), ele também apoiou a evolução do Mercado Comum Europeu e a emergência de uma identidade para a gestão europeia.

Segundo reportado em FNQ (FUNDAÇÃO..., 2008, p. 5), a premiação brasileira, denotada por Prêmio Nacional da Qualidade (PNQ), iniciou-se em 1991, sob a condução da Fundação para o Prêmio Nacional da Qualidade (FPNQ), criada nesse mesmo ano com a missão de "[...] disseminar os fundamentos da excelência em gestão para o aumento de competitividade das organizações e do Brasil." Posteriormente, essa entidade passou a ser nominada por Fundação Nacional da Qualidade (FNQ). FNQ (FUNDAÇÃO..., 2009) descreve o modelo de excelência em gestão (MEG) da FNQ. Observa-se que os componentes do MEG estão imersos em um ambiente de informações e conhecimento, encontram-se relacionados e voltados para a geração de resultados. 0 funcionamento do modelo é baseado no conceito do PDCL (plan, do, check, learn).

Ao comparar os critérios desses quatro prêmios, Vilas Boas e Costa (2013) destacam a preocupação apresentada pelo EFQMEA e pelo PNQ em relação à sociedade. 0 primeiro aborda as medidas de percepçõão e indicadores de desempenho, enquanto que o segundo preocupa-se com a responsabilidade socioambiental na promoção do desenvolvimento sustentável e social. Vilas Boas e Costa (2013) observam também a necessidade de se considerar o significado dos critérios e não apenas a sua nomenclatura, pois mesmo havendo coincidência de nomes de critérios, ocorrem diferenças conceituais entre eles.

\section{Abordagem proposta e caso de aplicação}

A abordagem proposta busca a classificação do grau de aderência organizacional às práticas de excelência em gestão, segundo critérios adaptados à organização. Essa modelagem está estruturada nas seguintes etapas: caracterizar a organização; especificar o conjunto de critérios de excelência a ser considerado; coletar autoavaliações sobre 0 desempenho da organização em cada critério e os seus respectivos pesos (ou graus de importância); aplicar o algoritmo de classificação do ELECTRE TRI e analisar os resultados. 
0 modelo proposto foi aplicado em um contexto de autoavaliação, em uma empresa do setor indústria têxtil, no segmento malharia, situada na cidade de Juiz de Fora, MG, Brasil. Trata-se de uma organização de médio porte que possui um sistema de gestão da qualidade implementado com base nas normas ISO 9000 e que nunca se candidatou a um prêmio de excelência em gestão. Essa organização é aqui denotada por Lab.

Deve-se considerar que, no âmbito dessa proposta, trata-se da apropriação de conceitos de um método de apoio multicritério de sobreclassificação para asolução de um problema de avaliação de desempenho. Esse tipo de abordagem foi efetuada de forma pioneira por Freitas e Costa (1998). Posteriormente, observa-se a aplicação do método ELECTRE TRI para avaliação da satisfação de clientes em: Costa e Freitas (2000), Politis e Siskos (2004), Costa et al. (2007), Freitas, Rodrigues e Costa (2009) e Freitas e Costa (2012). Assim como nesses trabalhos, na pesquisa efetuada não se fez uso do conceito de alternativa de escolha, mas do conceito "objeto sob avaliação". Isso foi feito para não criar no leitor a falsa impressão de que a modelagem busca a seleção de uma alternativa. Outro aspecto a ser considerado é que como as comparações são feitas em relação a classes de referência, não há a necessidade de ter-se vários objetos, não sendo proibitivo, em uma autoavaliação, avaliar e classificar um único objeto ou organização. Assim, a referida organização foi o objeto avaliado

Quadro 1. Escalas de valores para autoavaliação do desempenho e para atribuição de importância.

\begin{tabular}{|l|c|l|c|}
\hline \multicolumn{2}{|c|}{ Desempenho } & \multicolumn{2}{c|}{ Importância } \\
\hline Valor verbal & Valor numérico & Nível de importância & Valor numérico \\
\hline Muito ruim & -2 & Desprezível & 0 \\
\hline Ruim & -1 & Importância baixa & 1 \\
\hline Regular & 0 & Importância média & 2 \\
\hline Bom & 1 & Importância alta & 3 \\
\hline Muito bom & 2 & $\begin{array}{l}\text { Importância muito } \\
\text { alta }\end{array}$ & 4 \\
\hline
\end{tabular}

para fins de classificação quanto ao grau de aderência organizacional às práticas de excelência em gestão.

Para efeito do emprego do método ELECTRE TRl foram considerados como critérios os fatores de excelência em gestão (FEG) listados na primeira coluna dos Quadros 4, 5, 6, 7, 8, 9 e 10. A coleta de dados foi efetuada junto a um respondente pela organização, o qual era um dentre os três proprietários da empresa, o qual atuava como elemento principal na gestão. Nessa etapa, com o apoio das escalas reportadas no Quadro 1 e nas diretivas apontadas no Quadro 2, buscou-se captar a percepção do respondente quanto à importância ou influência de cada FEG para a organização e quanto ao desempenho da organização à luz de cada FEG. A definição das escalas seguiu os preceitos reportados em Likert (1932), Miller (1954), Luiz, Costa e Costa (2010) e Nepomuceno, Costa e Shimoda (2010): Likert (1932) indica que escalas para captar percepções devem apresentar opções simétricas; complementando essa orientação, Miller (1954) considera que, além de simétricas, as escalas devem disponibilizar 5 ou 9 opções; Nepomuceno, Costa e Shimoda (2010) propõem uma posição adicional na escala ( $N$, para aqueles que não souberem ou não desejarem opinar); e, Luiz, Costa e Costa (2010) agrupam esses conceitos, estabelecendo uma escala simétrica com cinco posições: $-2 ;-1 ; 0 ; 1$; e 2 , como pode ser visto no Quadro 1. É importante observar que, durante a avaliação, o respondente teve acesso apenas à escala verbal, sendo os valores numéricos do Quadro 1 utilizados apenas na fase de processamento pelo método ELECTRE TRI.

Para a categorização da organização foram definidas cinco classes de referência de desempenho: Muito bom (A), Bom (B), Regular (C), Ruim (D) e Muito ruim (E). Essas classes foram definidas de forma a guardar relação com a escala de desempenho ilustrada no Quadro 1. 0 Quadro 3 apresenta os limiares inferiores (assoalhos) dessas classes, os quais foram obtidos buscando guardar equidistância dos julgamentos coletados segundo a escala do Quadro 1: a distância entre os limiares das classes (Quadro 3)

Quadro 2. Orientações para autoavaliação.

\begin{tabular}{|l|l|}
\hline \multicolumn{2}{|c|}{ Orientações para a autoavaliação quanto ao desempenho } \\
\hline Muito ruim & Não existem evidências da questão em qualquer parte da organização, nem planejamento de ações para atendimento da questão. \\
\hline Ruim & A organização estabelece algumas ações para atendimento da questão de forma não sistemática. \\
\hline Regular & $\begin{array}{l}\text { A organização estabelece ações para atendimento da questão de forma sistemática em quase toda a organização, mas não } \\
\text { avalia os resultados. }\end{array}$ \\
\hline Bom & $\begin{array}{l}\text { A organização possui sistemática para atendimento da questão e os resultados obtidos servem de subsídio para correção e } \\
\text { validação ou padronização das ações em quase toda a organização. }\end{array}$ \\
\hline Muito bom & $\begin{array}{l}\text { São executadas ações em toda a organização, de forma sistêmica e padronizada, e os resultados obtidos servem como base } \\
\text { para novos patamares e metas desafiadoras. }\end{array}$ \\
\hline Não sei & $\begin{array}{l}\text { Não foi compreendido o propósito da questão, impedindo dessa forma uma resposta condizente com o assunto apresentado. } \\
\text { Ou não tenho informações suficientes para responder a essa questão. }\end{array}$ \\
\hline
\end{tabular}


e os valores contíguos a essas classes nas escalas de avaliação (Quadro 1) é igual à 0,5. Isso implica que, para qualquer critério j e qualquer limite de classe $b_{h}$, verifique-se $0 \leq q_{j}<p_{j}<0$,5. Outra consequência dos valores presentes no Quadro 3 é que o resultado da expressão $\left[g_{\mathrm{j}}(L a b)-g_{\mathrm{j}}\left(b_{\mathrm{h}}\right)\right]$ é um múltiplo de 0,5 , para quaisquer $\mathrm{j}$ e $\mathrm{h}$. Esses dois fatos resultam em que os valores possíveis de serem atribuídos a $q_{j}$ e $p_{j}$ não influenciam nos resultados obtidos para os graus de concordância e de credibilidade calculados através das expressões (1) e (3). Quanto ao veto, considerou-se que não se admitiria uma classificação $\mathrm{A}$, caso em algum FEG houvesse um desempenho Ruim ou Muito ruim. Essa conceituação implicou em um limite de veto $\left(v_{j}\right)$ igual a 2,5, obtido com base na Equação 2.

Observa-se ainda que no Quadro 3 consta uma coluna "indexação da classe" cujo objetivo é facilitar o entendimento da relação entre essas classes e a descrição matemática do algoritmo ELECTRE TRI, apresentada nas Equações 1, 2 e 3.

O ELECTRE TRI possui dois algoritmos de classificação, um menos exigente (tende a associar as alternativas às classes de melhor desempenho) e outro mais exigente (busca associar as alternativas às classes com pior desempenho). No caso específico da abordagem proposta no presente trabalho, optou-se pela classificação mais exigente pelo fato de ela imputar maior crítica à classificação obtida. Nessa classificação, compara-se, em cada critério, o desempenho atribuído à organização aos limites inferiores $\left(b_{h}\right)$ das classes $C_{1}, C_{2}$, $\mathrm{C}_{3}, \mathrm{C}_{4}$ e $\mathrm{C}_{5-}$ essa comparação é feita em acordo com as Equações 1 e 2. A partir dessas comparações obtêm-se pela aplicação da Equação 3 o grau de credibilidade $\left(\sigma\left(a, b_{h}\right)\right)$ em relação à afirmação de que o desempenho da organização é, no mínimo, equivalente ao da categoria $\mathrm{C}_{\mathrm{h}}$. Finalmente, compara-se $\sigma\left(\mathrm{a}, \mathrm{b}_{\mathrm{h}}\right)$ a um parâmetro de corte $\lambda$, em ordem descendente (da classe $C_{5}$ para a $C_{1}$ ), classificando-se a organização na primeira categoria para a qual se verifique que $\sigma\left(a, b_{h}\right) \geq \lambda$.

\section{Resultados}

Nessa seção apresentam-se as avaliações coletadas junto ao respondente e, também, as classificações obtidas pela aplicação do ELECTRE TRI aos dados

Quadro 3. Limiares inferiores das classes de referência

\begin{tabular}{|c|c|c|}
\hline Classe ou categoria & $\begin{array}{c}\text { Limite inferior } \\
\left(\mathbf{b}_{\mathbf{h}}\right)\end{array}$ & $\begin{array}{c}\text { Indexação da classe } \\
\left(\mathrm{C}_{\mathbf{h}}\right)\end{array}$ \\
\hline$A$ & $+1,5$ & $C_{5}$ \\
\hline$B$ & $+0,5$ & $C_{4}$ \\
\hline$C$ & $-0,5$ & $C_{3}$ \\
\hline$D$ & $-1,5$ & $C_{2}$ \\
\hline$E$ & $-2,5$ & $C_{1}$ \\
\hline
\end{tabular}

coletados. Os resultados são inicialmente apresentados para cada dimensão da excelência e, ao final, apresentados considerando todo o conjunto de FEGs.

\subsection{Dimensão liderança}

As autoavaliações de Lab na dimensão liderança são apresentadas no Quadro 4, juntamente com a importância atribuída a cada FEG e o grau de concordância, para cada FEG e cada classe de referência, em relação a afirmação de que Lab não é pior do que o limite inferior da classe.

Os dados do Quadro 5 foram inseridos nas Equações 1, 2 e 3, obtendo-se o grau de credibilidade da afirmação de que Lab está categorizada em determinada classe de referência, na dimensão liderança. Observa-se que o valor da credibilidade aumenta na direção da classe E. Isso é matematicamente coerente, visto que: $\mathrm{A} \subset \mathrm{B} \subset \mathrm{C} \subset \mathrm{D} \subset \mathrm{E}$; ou seja: $\mathrm{A}, \mathrm{B}, \mathrm{C}, \mathrm{D}$ e E não formam uma partição.

Aplicando-se um plano corte $(\lambda)$ igual a 0,75 aos dados ilustrados na Figura 2, classifica-se o desempenho de Lab na categoria B: a primeira, em ordem descendente, para qual a credibilidade é superior ou igual a 0,75 . Para que essa classificação seja elevada a classe A é necessário que:

- Se eleve o desempenho de Lab nos FEGs em que ela teve o desempenho Muito ruim, como forma de atender às restrições do limite de veto adotado $\left(v_{j}=2,5\right)$;

- Se eleve a Muito bom o desempenho de algum dos FEGs nos quais Lab teve uma avaliação abaixo de Muito bom, como forma de se elevar a credibilidade para o valor de 0,75 .

\subsection{Dimensão estratégias e planos}

As autoavaliações de Lab nessa dimensão estão apresentadas no Quadro 5, juntamente com a importância atribuída a cada FEG e o grau de

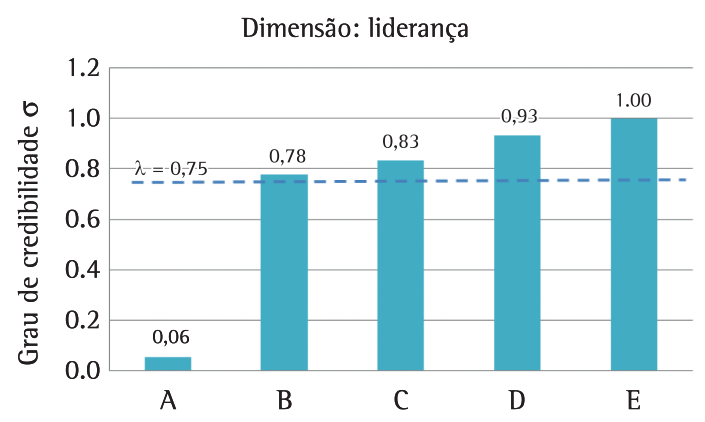

Figura 2. Graus de credibilidade versus Classes de referência: liderança. 
Costa, H. G. et al.

Modelo multicritério para avaliação ... proposta e caso de uso. Production, v. 24, n. 3, p. 521-535, July/Sept. 2014

Quadro 4. Resultados em relação à dimensão liderança.

\begin{tabular}{|c|c|c|c|c|c|c|c|}
\hline \multirow[b]{2}{*}{ FEG } & \multirow[b]{2}{*}{ Desempenho } & \multirow[b]{2}{*}{$\begin{array}{l}\text { Grau de } \\
\text { importância }\end{array}$} & \multicolumn{5}{|c|}{ Graus de credibilidade } \\
\hline & & & $\sigma\left(L a b, b_{h}(A)\right)$ & $\sigma\left(L a b, b_{h}(B)\right)$ & $\sigma\left(L a b, b_{h}(C)\right)$ & $\sigma\left(L a b, \mathrm{~b}_{\mathrm{h}}(D)\right)$ & $\sigma\left(L a b, b_{\mathrm{h}}(E)\right)$ \\
\hline Sistema de prestação de contas & Regular & Muito alta & 0 & 0 & 1 & 1 & 1 \\
\hline Tratamento dos riscos empresariais & Muito ruim & Alta & 0 & 0 & 0 & 0 & 1 \\
\hline $\begin{array}{l}\text { Ética nos relacionamentos interno } \\
\text { e externo }\end{array}$ & Bom & Muito alta & 0 & 1 & 1 & 1 & 1 \\
\hline Consolidação da missão e visão & Muito ruim & Muito alta & 0 & 0 & 0 & 0 & 1 \\
\hline Sistema de gestão & Bom & Muito alta & 0 & 1 & 1 & 1 & 1 \\
\hline $\begin{array}{l}\text { Interação com as partes interessadas } \\
\text { para a tomada de decisões }\end{array}$ & Bom & Muito alta & 0 & 1 & 1 & 1 & 1 \\
\hline Ambiente de trabalho & Bom & Muito alta & 0 & 1 & 1 & 1 & 1 \\
\hline $\begin{array}{l}\text { Promoção de uma cultura de } \\
\text { excelência }\end{array}$ & Bom & Muito alta & 0 & 1 & 1 & 1 & 1 \\
\hline $\begin{array}{l}\text { Sistemática de avaliação de } \\
\text { desempenho de diretores e chefes }\end{array}$ & Bom & Muito alta & 0 & 1 & 1 & 1 & 1 \\
\hline Gestão de lideranças & Bom & Muito alta & 0 & 1 & 1 & 1 & 1 \\
\hline Cultura de inovação & Ruim & Muito alta & 0 & 0 & 0 & 1 & 1 \\
\hline Gestão das parcerias externas & Muito bom & Muito alta & 1 & 1 & 1 & 1 & 1 \\
\hline $\begin{array}{l}\text { Gestão de materiais e suprimentos } \\
\text { para a produção }\end{array}$ & Bom & Muito alta & 0 & 1 & 1 & 1 & 1 \\
\hline Gestão da infraestrutura & Bom & Muito alta & 0 & 1 & 1 & 1 & 1 \\
\hline $\begin{array}{l}\text { Sistema de mensuração do } \\
\text { desempenho da organização }\end{array}$ & Bom & Muito alta & 0 & 1 & 1 & 1 & 1 \\
\hline $\begin{array}{l}\text { Comunicação do desempenho da } \\
\text { organização }\end{array}$ & Ruim & Alta & 0 & 0 & 0 & 1 & 1 \\
\hline $\begin{array}{l}\text { Sensibilidade do sistema de } \\
\text { mensuração de desempenho às } \\
\text { mudanças organizacionais }\end{array}$ & Bom & Muito alta & 0 & 1 & 1 & 1 & 1 \\
\hline $\begin{array}{l}\text { Sistemática de comparação do } \\
\text { desempenho com referenciais } \\
\text { externos pertinentes }\end{array}$ & Muito ruim & Média & 0 & 0 & 0 & 0 & 1 \\
\hline $\begin{array}{l}\text { Melhoria do desempenho da } \\
\text { organização e implementação de } \\
\text { inovações }\end{array}$ & Bom & Muito alta & 0 & 1 & 1 & 1 & 1 \\
\hline
\end{tabular}

Quadro 5. Resultados em relação à dimensão estratégias e planos.

\begin{tabular}{|c|c|c|c|c|c|c|c|}
\hline \multirow[b]{2}{*}{ FEG } & \multirow[b]{2}{*}{ Desempenho } & \multirow[b]{2}{*}{$\begin{array}{l}\text { Grau de } \\
\text { importância }\end{array}$} & \multicolumn{5}{|c|}{ Graus de concordância } \\
\hline & & & $\sigma\left(L a b, \mathrm{~b}_{\mathrm{h}}(A)\right)$ & $\sigma\left(L a b, \mathrm{~b}_{\mathrm{h}}(B)\right)$ & $\sigma\left(L a b, \mathrm{~b}_{h}(C)\right)$ & $\sigma\left(L a b, b_{h}(D)\right)$ & $\sigma\left(L a b, b_{h}(E)\right)$ \\
\hline $\begin{array}{l}\text { Coerência com os requisitos das } \\
\text { partes interessadas }\end{array}$ & Muito bom & Muito alta & 1 & 1 & 1 & 1 & 1 \\
\hline $\begin{array}{l}\text { Coerência com as análises de } \\
\text { ambiente interno e externo }\end{array}$ & Bom & Muito alta & 0 & 1 & 1 & 1 & 1 \\
\hline $\begin{array}{l}\text { Envolvimento de todas as áreas } \\
\text { da organização no processo de } \\
\text { formulação das estratégias }\end{array}$ & Muito ruim & Muito alta & 0 & 0 & 0 & 0 & 1 \\
\hline $\begin{array}{l}\text { Sistemática de revisão das } \\
\text { estratégias }\end{array}$ & Ruim & Muito alta & 0 & 0 & 0 & 1 & 1 \\
\hline $\begin{array}{l}\text { Desdobramento das estratégias em } \\
\text { planos de ação }\end{array}$ & Regular & Muito alta & 0 & 0 & 1 & 1 & 1 \\
\hline $\begin{array}{l}\text { Eficácia da implementação das } \\
\text { estratégias }\end{array}$ & Regular & Muito alta & 0 & 0 & 1 & 1 & 1 \\
\hline $\begin{array}{l}\text { Comunicação das estratégias e } \\
\text { planos }\end{array}$ & Regular & Muito alta & 0 & 0 & 1 & 1 & 1 \\
\hline $\begin{array}{l}\text { Capacidade da organização de } \\
\text { realizar seus planos de ação }\end{array}$ & Bom & Alta & 0 & 1 & 1 & 1 & 1 \\
\hline $\begin{array}{l}\text { Capacidade da organização de } \\
\text { alterar seus planos de ação }\end{array}$ & Muito bom & Muito alta & 1 & 1 & 1 & 1 & 1 \\
\hline
\end{tabular}


concordância, para cada FEG e cada classe de referência, em relação à afirmação de que Lab não é pior do que o limite inferior da classe. A Figura 3 ilustra os graus de credibilidade obtidos pela aplicação do conjunto de Equações 1, 2 e 3 a esses dados. Adotando-se $\lambda=0,75$, classifica-se Lab na classe $C$ (Regular).

É interessante notar que para que a organização seja classificada na classe B é necessário que ela alcance o conceito Bom em pelo menos mais quatro FEGs, dentre aqueles em que ela teve o desempenho avaliado como Muito ruim, Ruim, ou Regular - a elevação do desempenho nesses FEGs resultaria em $\sigma\left(L a b, b_{h}(B)\right)>0,75$, o que possibilitaria a classificação

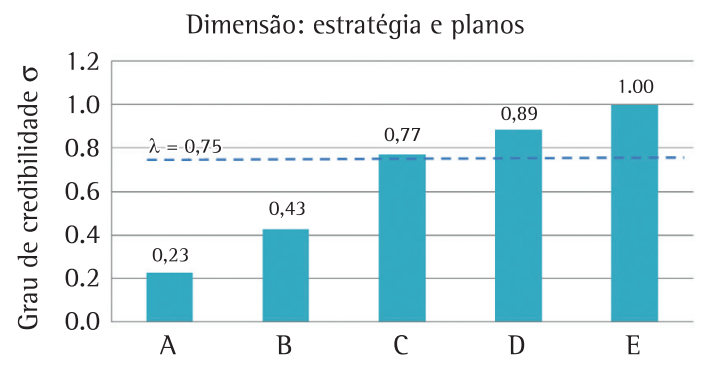

Figura 3. Graus de credibilidade versus Classes de referência: estratégias e planos. de Lab no nível B. De um ponto de vista de mínimo esforço, Lab deveria buscar esses desempenhos nos três FEGS que têm desempenho Regular e no FEG que tem desempenho Ruim, pois esses estão mais próximos do conceito Bom e provavelmente demandariam menor esforço para elevação do nível de desempenho da organização. Por outro lado, essa decisão implicaria em manter um quesito com o desempenho Muito ruim, o que não é desejável. Assim, para que a organização atinja a classe B na dimensão estratégias e planos, recomenda-se que ela priorize elevar o seu desempenho à categoria Bom nos FEGs em que teve o desempenho Muito ruim e Ruim e, também, em dois dos FEGs com desempenho Regular.

\subsection{Dimensão clientes}

0 Quadro 6 apresenta as respostas referentes à dimensão clientes e os graus de credibilidade com relação à afirmação de que a organização está categorizada em determinada classe, nessa dimensão. Ao passo que a Figura 4 apresenta os valores calculados para a credibilidade.

Aplicando-se um plano de corte (l) igual a 0,75, classifica-se na classe B (Bom) o desempenho de Lab à luz das práticas de excelência em gestão na dimensão clientes. Destaca-se que essa mesma classificação seria

Quadro 6. Resultados em relação à dimensão clientes.

\begin{tabular}{|c|c|c|c|c|c|c|c|}
\hline \multirow[b]{2}{*}{ FEG } & \multirow[b]{2}{*}{ Desempenho } & \multirow[b]{2}{*}{ Importância } & \multicolumn{5}{|c|}{ Graus de concordância } \\
\hline & & & $\sigma\left(L a b, b_{h}(A)\right)$ & $\sigma\left(L a b, \mathrm{~b}_{\mathrm{h}}(B)\right)$ & $\sigma\left(L a b, \mathrm{~b}_{\mathrm{h}}(C)\right)$ & $\sigma\left(L a b, b_{h}(D)\right)$ & $\sigma\left(L a b, b_{h}(E)\right)$ \\
\hline Segmentação de clientes & Bom & Muito alta & 0 & 1 & 1 & 1 & 1 \\
\hline $\begin{array}{l}\text { Conhecimento das necessidades e } \\
\text { expectativas dos clientes }\end{array}$ & Muito bom & Muito alta & 1 & 1 & 1 & 1 & 1 \\
\hline Definição e melhoria dos produtos & Muito bom & Muito alta & 0 & 1 & 1 & 1 & 1 \\
\hline Divulgação dos produtos e marcas & Ruim & Média & 0 & 0 & 0 & 0 & 1 \\
\hline Imagem da organização & Muito bom & Muito alta & 1 & 1 & 1 & 1 & 1 \\
\hline Canais de comunicação & Muito bom & Muito alta & 1 & 1 & 1 & 1 & 1 \\
\hline $\begin{array}{l}\text { Diferenciação dos canais de } \\
\text { comunicação para atender } \\
\text { diferentes grupos de clientes }\end{array}$ & Bom & Muito alta & 0 & 1 & 1 & 1 & 1 \\
\hline $\begin{array}{l}\text { Sistemática de atendimento das } \\
\text { reclamações e solicitações de } \\
\text { clientes }\end{array}$ & Bom & Muito alta & 0 & 1 & 1 & 1 & 1 \\
\hline $\begin{array}{l}\text { Sistemática de mensuração da } \\
\text { satisfação e insatisfação de clientes }\end{array}$ & Bom & Muito alta & 0 & 1 & 1 & 1 & 1 \\
\hline $\begin{array}{l}\text { Sistemática de fidelização de } \\
\text { clientes }\end{array}$ & Muito bom & Muito alta & 1 & 1 & 1 & 1 & 1 \\
\hline $\begin{array}{l}\text { Estabelecimento de parcerias com } \\
\text { clientes }\end{array}$ & Muito bom & Muito alta & 1 & 1 & 1 & 1 & 1 \\
\hline $\begin{array}{l}\text { Cultura organizacional focada no } \\
\text { cliente }\end{array}$ & Bom & Muito alta & 0 & 1 & 1 & 1 & 1 \\
\hline $\begin{array}{l}\text { Utilização de informações de } \\
\text { clientes }\end{array}$ & Bom & Alta & 0 & 1 & 1 & 1 & 1 \\
\hline $\begin{array}{l}\text { Sistemática de comparação dos } \\
\text { resultados relativos aos clientes com } \\
\text { referenciais externos pertinentes }\end{array}$ & Muito ruim & Média & 0 & 0 & 0 & 0 & 1 \\
\hline
\end{tabular}


obtida para um grau de credibilidade mais exigente (para $\lambda \leq$ a 0,92 ). Para que se eleve a classificação da organização à classe $A$, é necessário que se eleve ao nível Muito bom o desempenho de pelo menos quatro FEGs com importância Muito alta.

\subsection{Dimensão sociedade}

0 Quadro 7 apresenta as autoavaliações coletadas nos FEGs referentes à dimensão sociedade. Adotando $\lambda=0,75$, observa-se na Figura 5 que Lab é classificado na classe E. Esse resultado é coerente, visto que

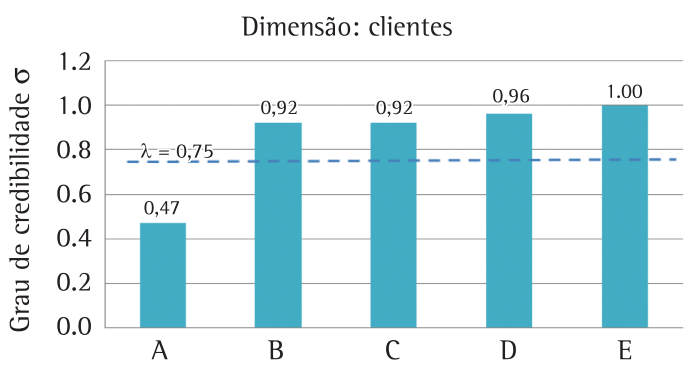

Figura 4. Graus de credibilidade versus Classes de referência: clientes. nessa dimensão Lab apresentou FEG com o menor desempenho. Para que se eleve a classificação à classe C, é necessário elevar todos os desempenhos dos FEGs avaliados como Muito ruim e importância Alta ou Muito alta ao nível Regular, além de elevar um critério com importância média ao nível de desempenho Regular - essas ações implicarão em uma credibilidade de que a organização está categorizada na classe $\mathrm{C}$ igual a 0,80 .

\subsection{Dimensão gestão de informações e do conhecimento}

0 Quadro 8 exibe os dados coletados nos FEGs referentes à dimensão gestão de informações e do conhecimento, ao passo que a Figura 6 indica os graus de credibilidade. Aplicando-se um plano de corte (I) igual a 0,75 a esses dados, classifica-se Lab na classe C (Regular). Para elevar a classificação da organização à classe $\mathrm{B}$, recomenda-se que se eleve ao nível Bom o desempenho dos dois FEGs cujo desempenho tenha sido classificado como Muito ruim e o desempenho de mais um FEG cuja performance tenha sido classificada como Regular e cuja importância tenha sido reconhecida como Muito alta.

Quadro 7. Resultados em relação à dimensão sociedade.

\begin{tabular}{|c|c|c|c|c|c|c|c|}
\hline \multirow[b]{2}{*}{ FEG } & \multirow[b]{2}{*}{ Desempenho } & \multirow[b]{2}{*}{ Importância } & \multicolumn{5}{|c|}{ Graus de concordância } \\
\hline & & & $\sigma\left(L a b, \mathrm{~b}_{\mathrm{h}}(A)\right)$ & $\sigma\left(L a b, b_{h}(B)\right)$ & $\sigma\left(L a b, b_{h}(C)\right)$ & $\sigma\left(L a b, \mathrm{~b}_{\mathrm{h}}(D)\right)$ & $\sigma\left(L a b, \mathbf{b}_{\mathrm{h}}(E)\right)$ \\
\hline $\begin{array}{l}\text { ldentificação dos impactos de } \\
\text { seus produtos e operações nas } \\
\text { comunidades locais }\end{array}$ & Muito bom & Muito alta & 0 & 1 & 1 & 1 & 1 \\
\hline $\begin{array}{l}\text { Tratamento dos impactos de } \\
\text { seus produtos e operações nas } \\
\text { comunidades locais }\end{array}$ & Bom & Muito alta & 1 & 1 & 1 & 1 & 1 \\
\hline $\begin{array}{l}\text { Preparo da organização para a } \\
\text { ocorrência de eventuais situações de } \\
\text { emergência e potenciais acidentes }\end{array}$ & Muito ruim & Muito alta & 0 & 1 & 1 & 1 & 1 \\
\hline $\begin{array}{l}\text { Cumprimento dos requisitos legais, } \\
\text { regulamentares e contratuais } \\
\text { aplicáveis a questões socioambientais }\end{array}$ & Bom & Muito alta & 0 & 0 & 0 & 0 & 1 \\
\hline $\begin{array}{l}\text { Comunicação dos impactos sociais } \\
\text { e ambientais de seus produtos } \\
\text { e de sua operação à sociedade, } \\
\text { incluindo as comunidades vizinhas }\end{array}$ & Muito ruim & Média & 1 & 1 & 1 & 1 & 1 \\
\hline $\begin{array}{l}\text { Conhecimento das necessidades } \\
\text { e expectativas da sociedade e } \\
\text { comunidades vizinhas }\end{array}$ & Regular & Média & 1 & 1 & 1 & 1 & 1 \\
\hline Implementação de projetos sociais & Muito ruim & Alta & 0 & 1 & 1 & 1 & 1 \\
\hline $\begin{array}{l}\text { Envolvimento das partes } \\
\text { interessadas na implementação e } \\
\text { apoio aos projetos sociais }\end{array}$ & Muito ruim & Alta & 0 & 1 & 1 & 1 & 1 \\
\hline $\begin{array}{l}\text { Sistema de mensuração da satisfação } \\
\text { da sociedade ou comunidades } \\
\text { vizinhas }\end{array}$ & Muito ruim & Média & 0 & 1 & 1 & 1 & 1 \\
\hline $\begin{array}{l}\text { Sistemática de comparação dos } \\
\text { resultados relativos a ações sociais } \\
\text { com referenciais externos pertinentes }\end{array}$ & Muito ruim & Média & 1 & 1 & 1 & 1 & 1 \\
\hline
\end{tabular}




\subsection{Dimensão pessoas}

0 Quadro 9 apresenta as avaliações coletadas nos FEGs referentes à dimensão pessoas, ao passo que a Figura 7 apresenta os graus de credibilidade associados à afirmação de que Lab está categorizada em determinada classe nessa dimensão. Adotando $1=0,75$, classifica-se na classe C (Média) o desempenho de Lab quanto a práticas de excelência em gestão na dimensão pessoas. Para que se eleve a classificação para a classe B é necessário que se atue em pelo menos oito FEGs, elevando o desempenho desses ao nível Bom. A recomendação à organização é que essa elevação seja efetuada nos critérios em que a organização teve desempenho Muito ruim e em mais seis critérios de importância Muito alta, nos quais ela tenha tido um desempenho Regular.

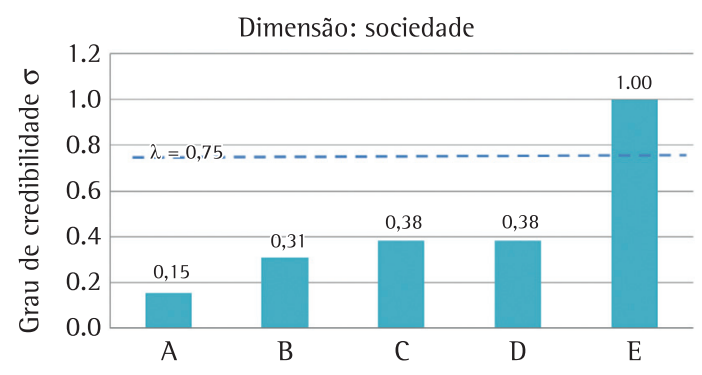

Figura 5. Graus de credibilidade versus Classes de referência: sociedade.
Dimensão: gestão de informações e do conhecimento

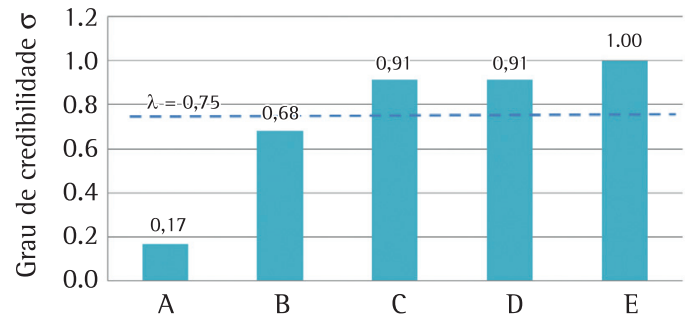

Figura 6. Graus de credibilidade versus Classes de referência: gestão de informações e do conhecimento.

Quadro 8. Resultados em relação à dimensão gestão de informações e do conhecimento.

\begin{tabular}{|c|c|c|c|c|c|c|c|}
\hline \multirow[b]{2}{*}{ Fator de excelência em gestão } & \multirow[b]{2}{*}{ Desempenho } & \multirow[b]{2}{*}{ Importância } & \multicolumn{5}{|c|}{ Graus de concordância } \\
\hline & & & $\sigma\left(L a b, b_{h}(A)\right)$ & $\sigma\left(L a b, \mathrm{~b}_{\mathrm{h}}(B)\right)$ & $\sigma\left(L a b, b_{h}(C)\right)$ & $\sigma\left(L a b, b_{h}(D)\right)$ & $\sigma\left(L a b, \mathrm{~b}_{\mathrm{h}}(E)\right)$ \\
\hline $\begin{array}{l}\text { Sistemática de identificação das } \\
\text { informações necessárias para os } \\
\text { principais níveis da organização }\end{array}$ & Bom & Muito alta & 0 & 1 & 1 & 1 & 1 \\
\hline $\begin{array}{l}\text { Interação com os funcionários para } \\
\text { a identificação das informações } \\
\text { necessárias para a realização de } \\
\text { suas atividades }\end{array}$ & Muito bom & Muito alta & 1 & 1 & 1 & 1 & 1 \\
\hline Disponibilização das informações & Bom & Muito alta & 0 & 1 & 1 & 1 & 1 \\
\hline $\begin{array}{l}\text { Mecanismos que asseguram a } \\
\text { atualização, confidencialidade e } \\
\text { integridade das informações }\end{array}$ & Bom & Muito alta & 0 & 1 & 1 & 1 & 1 \\
\hline $\begin{array}{l}\text { Utilização das informações na } \\
\text { melhoria do desempenho }\end{array}$ & Bom & Muito alta & 0 & 1 & 1 & 1 & 1 \\
\hline $\begin{array}{l}\text { Atualização tecnológica dos } \\
\text { sistemas de informação utilizados } \\
\text { pela organização }\end{array}$ & Muito bom & Muito alta & 1 & 1 & 1 & 1 & 1 \\
\hline $\begin{array}{l}\text { Utilização da tecnologia da } \\
\text { informação na alavancagem do } \\
\text { negócio e promoção da integração } \\
\text { com os clientes, fornecedores e } \\
\text { parceiros }\end{array}$ & Bom & Muito alta & 0 & 1 & 1 & 1 & 1 \\
\hline $\begin{array}{l}\text { Disponibilização contínua dos } \\
\text { sistemas de hardware e software, } \\
\text { dados e informações em caso de } \\
\text { emergência }\end{array}$ & Bom & Muito alta & 0 & 1 & 1 & 1 & 1 \\
\hline $\begin{array}{l}\text { Utilização de informações } \\
\text { comparativas } \\
\end{array}$ & Muito ruim & Média & 0 & 0 & 0 & 0 & 1 \\
\hline Identificação dos ativos intangíveis & Regular & Alta & 0 & 0 & 1 & 1 & 1 \\
\hline $\begin{array}{l}\text { Retenção e proteção dos principais } \\
\text { ativos intangiveis }\end{array}$ & Muito ruim & Média & 0 & 0 & 0 & 0 & 1 \\
\hline \begin{tabular}{|l|} 
Compartilhamento do conhecimento \\
relevante para a agregação de valor \\
ao negócio entre os funcionários \\
\end{tabular} & Regular & Muito alta & 0 & 0 & 1 & 1 & 1 \\
\hline $\begin{array}{l}\text { Retenção de pessoas consideradas } \\
\text { chave para o sucesso organizacional }\end{array}$ & Regular & Muito alta & 0 & 0 & 1 & 1 & 1 \\
\hline
\end{tabular}




\subsection{Dimensão processos}

O Quadro 10 exibe as avaliações coletadas nos FEGs referentes à dimensão processos. Observa-se que apesar da existência de um conjunto de critérios com desempenho Muito bom (três), há um número significativo de critérios (seis) nos quais o desempenho da organização foi considerado Muito ruim. Dois desses FEGs com importância Muito alta, três com

Dimensão: pessoas

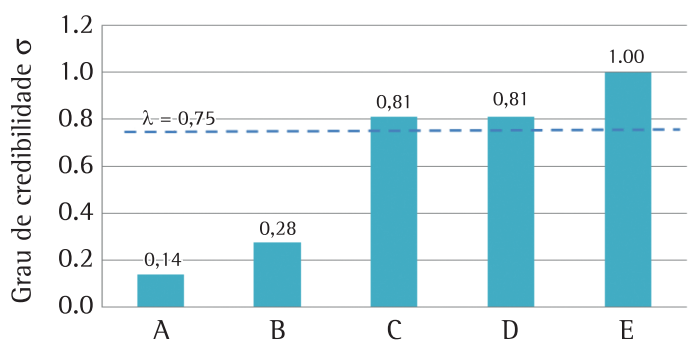

Figura 7. Graus de credibilidade versus Classes de referência: pessoas. importância Média e um com importância Alta. A Figura 8 apresenta os graus de credibilidade com relação àafirmação de que Lab está categorizada em determinada classe, nessa dimensão. Para um plano de corte (l) igual a 0,75 , classifica-se Lab na classe $E$ (Muito baixa). Uma análise de sensibilidade baseada nesses dados indica que basta à organização elevar o seu desempenho a Regula nos dois critérios com desempenho Muito ruim e importância Muito alta

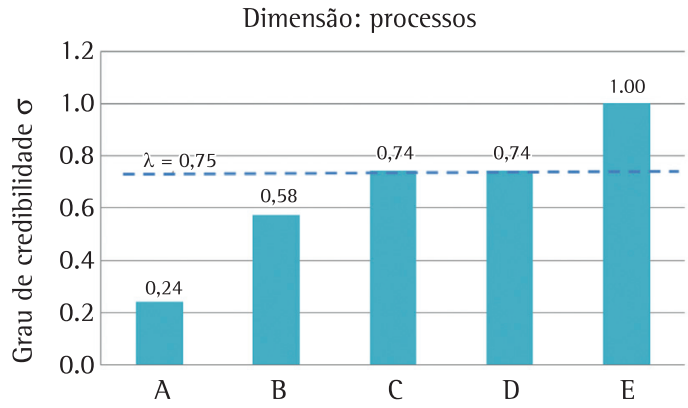

Figura 8. Graus de credibilidade versus Classes de referência: processos.

Quadro 9. Resultados em relação à dimensão pessoas.

\begin{tabular}{|c|c|c|c|c|c|c|c|}
\hline & & & & Graus de co & cordância & & \\
\hline FEG & Desempenho & Importância & $\sigma\left(L a b, b_{h}(A)\right)$ & $\sigma\left(L a b, \mathbf{b}_{h}(B)\right)$ & $\sigma\left(L a b, \mathrm{~b}_{\mathrm{h}}(C)\right)$ & $\sigma\left(L a b, b_{\mathrm{h}}(D)\right)$ & $\sigma\left(L a b, \mathbf{b}_{\mathrm{h}}(E)\right)$ \\
\hline Estruturação de cargos & Regular & Muito alta & 0 & 0 & 1 & 1 & 1 \\
\hline $\begin{array}{l}\text { Seleção e contratação de } \\
\text { funcionários }\end{array}$ & Regular & Muito alta & 0 & 0 & 1 & 1 & 1 \\
\hline $\begin{array}{l}\text { Integração das pessoas } \\
\text { recém-contratadas na cultura } \\
\text { organizacional }\end{array}$ & Muito bom & Muito alta & 1 & 1 & 1 & 1 & 1 \\
\hline $\begin{array}{l}\text { Canais de comunicação da } \\
\text { organização com os funcionários }\end{array}$ & Regular & Muito alta & 0 & 0 & 1 & 1 & 1 \\
\hline $\begin{array}{l}\text { Avaliação de desempenho dos } \\
\text { funcionários }\end{array}$ & Regular & Muito alta & 0 & 0 & 1 & 1 & 1 \\
\hline Satisfação dos funcionários & Regular & Muito alta & 0 & 0 & 1 & 1 & 1 \\
\hline $\begin{array}{l}\text { Oferecimento de estímulos aos } \\
\text { funcionários através de incentivos, } \\
\text { remuneração e reconhecimento }\end{array}$ & Regular & Muito alta & 0 & 0 & 1 & 1 & 1 \\
\hline $\begin{array}{l}\text { Capacitação e desenvolvimento de } \\
\text { funcionários }\end{array}$ & Regular & Muito alta & 0 & 0 & 1 & 1 & 1 \\
\hline $\begin{array}{l}\text { Eficácia dos programas de } \\
\text { capacitação }\end{array}$ & Regular & Alta & 0 & 0 & 1 & 1 & 1 \\
\hline $\begin{array}{l}\text { Desenvolvimento de carreira e } \\
\text { progressão }\end{array}$ & Muito ruim & Alta & 0 & 0 & 0 & 0 & 1 \\
\hline $\begin{array}{l}\text { Comprometimento da força de } \\
\text { trabalho }\end{array}$ & Muito bom & Muito alta & 1 & 1 & 1 & 1 & 1 \\
\hline $\begin{array}{l}\text { Atuação sobre os perigos e riscos } \\
\text { relacionados a saúde ocupacional, } \\
\text { segurança e ergonomia }\end{array}$ & Bom & Muito alta & 0 & 1 & 1 & 1 & 1 \\
\hline $\begin{array}{l}\text { Tratamento dos fatores que afetam } \\
\text { o bem-estar e a satisfação das } \\
\text { pessoas }\end{array}$ & Bom & Muito alta & 0 & 1 & 1 & 1 & 1 \\
\hline $\begin{array}{l}\text { Oferta de serviços e benefícios aos } \\
\text { funcionários }\end{array}$ & Muito ruim & Muito alta & 0 & 0 & 0 & 0 & 1 \\
\hline $\begin{array}{l}\text { Melhoria da qualidade de vida } \\
\text { das pessoas fora do ambiente de } \\
\text { trabalho }\end{array}$ & Muito ruim & Muito alta & 0 & 0 & 0 & 0 & 1 \\
\hline
\end{tabular}


para que ela seja classificada na classe C. Para que possa ser categorizada na classe B é indicado que eleve ao nível Bom o seu desempenho em todos os critérios nos quais obteve desempenho Muito ruim - com essa medida ocorreria uma credibilidade igual a 0,79 e Lab seria classe B.

\subsection{Classificação com base em todo o conjunto de critérios}

Com a aplicação das Equações 1, 2 e 3 às autoavaliações coletadas junto ao respondente e apresentadas nos tópicos anteriores foi elaborada

Quadro 10. Resultados em relação à dimensão processos.

\begin{tabular}{|c|c|c|c|c|c|c|c|}
\hline \multirow{2}{*}{\begin{tabular}{|c|} 
FEG \\
\end{tabular}} & \multirow[b]{2}{*}{ Desempenho } & \multicolumn{6}{|c|}{ Graus de concordância } \\
\hline & & lmportância & $\sigma\left(L a b, \mathrm{~b}_{\mathrm{h}}(A)\right)$ & $\sigma\left(L a b, \mathrm{~b}_{\mathrm{h}}(B)\right)$ & $\sigma\left(L a b, \mathrm{~b}_{\mathrm{h}}(C)\right)$ & $\sigma\left(L a b, \mathrm{~b}_{\mathrm{h}}(D)\right)$ & $\sigma\left(L a b, \mathrm{~b}_{\mathrm{h}}(E)\right)$ \\
\hline $\begin{array}{l}\text { Capitalizam as principais } \\
\text { competências da organização }\end{array}$ & Muito bom & Muito alta & 1 & 1 & 1 & 1 & 1 \\
\hline $\begin{array}{l}\text { Relacionam a ocorrência de } \\
\text { catástrofes ou situações de } \\
\text { emergência }\end{array}$ & Muito ruim & Muito alta & 0 & 0 & 0 & 0 & 1 \\
\hline $\begin{array}{l}\text { Preparação do local de trabalho } \\
\text { para a ocorrência de catástrofes } \\
\text { ou situações de emergência }\end{array}$ & Muito ruim & Muito alta & 0 & 0 & 0 & 0 & 1 \\
\hline $\begin{array}{l}\text { Concepção dos processos principais } \\
\text { no que se refere à incorporação dos } \\
\text { requisitos das partes interessadas }\end{array}$ & Muito bom & Muito alta & 1 & 1 & 1 & 1 & 1 \\
\hline $\begin{array}{l}\text { Monitoramento dos processos } \\
\text { principais }\end{array}$ & Muito bom & Muito alta & 1 & 1 & 1 & 1 & 1 \\
\hline $\begin{array}{l}\text { Concepção dos processos de apoio } \\
\text { no que se refere à incorporação } \\
\text { das necessidades dos funcionários }\end{array}$ & Regular & Muito alta & 0 & 0 & 1 & 1 & 1 \\
\hline $\begin{array}{l}\text { Monitoramento dos processos } \\
\text { de apoio }\end{array}$ & Bom & Alta & 0 & 1 & 1 & 1 & 1 \\
\hline $\begin{array}{l}\text { Melhoria dos processos principais } \\
\text { e de apoio }\end{array}$ & Bom & Alta & 0 & 1 & 1 & 1 & 1 \\
\hline $\begin{array}{l}\text { Sistemática de comparação dos } \\
\text { resultados dos processos principais } \\
\text { com referenciais externos } \\
\text { pertinentes }\end{array}$ & Muito ruim & Média & 0 & 0 & 0 & 0 & 1 \\
\hline $\begin{array}{l}\text { Seleção e qualificação de } \\
\text { fornecedores }\end{array}$ & Bom & Muito alta & 0 & 1 & 1 & 1 & 1 \\
\hline $\begin{array}{l}\text { Desenvolvimento de parcerias e da } \\
\text { cadeia de suprimentos }\end{array}$ & Muito bom & Muito alta & 1 & 1 & 1 & 1 & 1 \\
\hline $\begin{array}{l}\text { Erradicação do trabalho infantil e } \\
\text { trabalho degradante e forçado na } \\
\text { cadeia de suprimentos }\end{array}$ & Bom & Muito alta & 0 & 1 & 1 & 1 & 1 \\
\hline $\begin{array}{l}\text { Avaliação do desempenho de } \\
\text { fornecedores }\end{array}$ & Regular & Muito alta & 0 & 0 & 1 & 1 & 1 \\
\hline $\begin{array}{l}\text { Comunicação com os fornecedores } \\
\text { sobre seu desempenho }\end{array}$ & Regular & Alta & 0 & 0 & 1 & 1 & 1 \\
\hline $\begin{array}{l}\text { Comprometimento dos principais } \\
\text { fornecedores com os princípios } \\
\text { organizacionais, incluindo os } \\
\text { relativos à responsabilidade } \\
\text { socioambiental e à saúde e } \\
\text { segurança }\end{array}$ & Muito ruim & Alta & 0 & 0 & 0 & 0 & 1 \\
\hline $\begin{array}{l}\text { Sistemática de comparação dos } \\
\text { resultados dos fornecedores com } \\
\text { referenciais externos pertinentes }\end{array}$ & Muito ruim & Média & 0 & 0 & 0 & 0 & 1 \\
\hline $\begin{array}{l}\text { Gestão dos recursos financeiros } \\
\text { necessários para atender as } \\
\text { necessidades operacionais }\end{array}$ & Bom & Muito alta & 0 & 1 & 1 & 1 & 1 \\
\hline $\begin{array}{l}\text { Gestão da sustentabilidade } \\
\text { econômica }\end{array}$ & Bom & Muito alta & 0 & 1 & 1 & 1 & 1 \\
\hline $\begin{array}{l}\text { Sistemática de comparação } \\
\text { dos resultados de desempenho } \\
\text { econômico-financeiros com } \\
\text { referenciais externos pertinentes }\end{array}$ & Muito ruim & Média & 0 & 0 & 0 & 0 & 1 \\
\hline
\end{tabular}


Geral

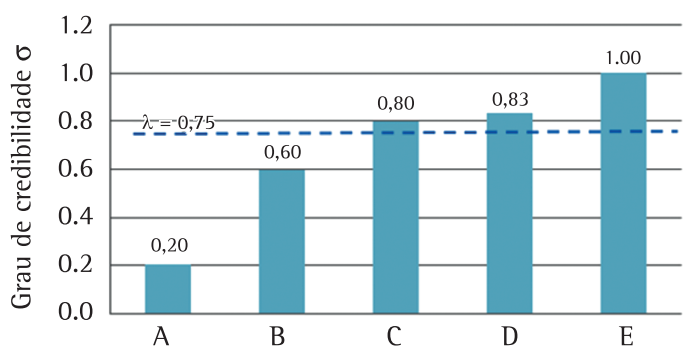

Figura 9. Graus de credibilidade versus Classes de referência: geral.

a Figura 9, que ilustra os graus de credibilidade com relação à afirmação de que a organização está categorizada em determinada classe, considerando todo o conjunto de FEGs. Aplicando-se um plano de corte (l) igual a 0,75 aos dados ilustrados nesse quadro classifica-se o desempenho da organização à luz das práticas de excelência em gestão na classe C.

\section{Conclusões}

Esta pesquisa incorporou ao modelo proposto por Vilas Boas e Costa (2013) a capacidade de classificação de organizações quanto ao seu desempenho à luz das práticas de excelência em gestão, com base em uma abordagem multicritério balanceada (ou não compensatória).

As dimensões de excelência consideradas (liderança; estratégias e planos; clientes; sociedade; gestão de informações e do conhecimento; pessoas; e processos) foram estruturadas em fatores de excelência em gestão (FEGs). Os resultados obtidos da aplicação do modelo multicritério proposto a um caso específico possibilitaram identificar tanto a classificação geral da organização pesquisada, considerando o conjunto de FEGs, quanto a classificação dela em cada um dos critérios de excelência. Essa estratégia permitiu identificar que:

- Clientes foi o critério em que a organização obteve a sua melhor classificação (classe B: Bom desempenho, com um grau de credibilidade igual a 0,92), tendo sido indicados os FEGs em que ela deveria elevar o seu desempenho para atingir uma melhor classificação (classe A: desempenho Muito bom);

- Sociedade e processos, nessa ordem, foram as dimensões em que a organização obteve o seu pior desempenho, tendo sido classificada em ambos os critérios na categoria E (desempenho Muito ruim), que é a pior classe de referência do modelo. No caso do critério processos ainda houve alguns quesitos ou FEGs em que a organização alcançou o desempenho Muito bom. No entanto, no caso do critério sociedade, só houve um FEG no qual a organização atingiu esse nível de desempenho. As classificações foram analisadas, sendo sugeridos os FEGs a serem priorizados para que a organização eleve a sua classificação;

- Nos demais critérios de excelência, a organização foi classificada na categoria C (desempenho Médio), tendo sido identificados, em cada critério, os FEGs a serem priorizados para que ela alcance o nível de excelência B.

$\mathrm{Na}$ modelagem proposta, a análise global do desempenho da organização indicou que a mesma estaria classificada na classe C. Como essa modelagem considera a homogeneidade e o equilíbrio no desempenho, para que se eleve o desempenho global da organização à categoria B é necessário que ela aumente o desempenho ao nível Bom nas dimensões onde ele é inferior a Bom, sendo inócuo (para fins da mudança da classificação) elevar o desempenho na dimensão clientes.

A simulação a seguir, com base nos dados coletados para a dimensão liderança, é efetuada com o intuito de destacar a diferença nos resultados obtidos pela aplicação de um algoritmo de classificação compensatório (média ponderada) e daqueles obtidos pelo uso de um método não compensatório (ELCTRE TRI).

Suponha que o desempenho de Lab nos três FEGs em que ela obteve o desempenho Muito ruim fosse elevada ao nível Ruim: utilizando-se a média ponderada, Lab obteria uma média igual a 0,56 , que quando comparada ao "assoalho" da classe B, classificaria Lab nessa categoria (classe B, desempenho Bom), apesar do desempenho de Lab ter sido alterado apenas pela elevação de seu desempenho de Muito ruim para Ruim em três FEGs. Por outro lado, ao se aplicar a modelagem proposta no presente trabalho, o desempenho de Lab permaneceria classificado na categoria C, pois não se considera que a elevação de desempenho de Lab para níveis inferiores a Bom seja um argumento que justifique que o desempenho de Lab passe a ser categorizado como Bom.

Observa-se, então, que a modelagem aqui apresentada provê uma avaliação mais balanceada do que os métodos compensatórios, nos quais pode-se elevar uma classificação de forma não balanceada.

Como sugestão para futuros desenvolvimentos, sugere-se verificar a possibilidade e os efeitos da incorporação de critérios de sustentabilidade, ética empresarial, responsabilidade social e transparência de negócios ao conjunto de critérios e de fatores de excelência em gestão.

\section{Referências}

ALENCAR, L. H.; ALMEIDA, A. T.; MOTA, C. M. M. Sistemática proposta para seleção de fornecedores em gestão de projetos. Gestão \& Produção, v. 14, n. 3, p. 477487, 2007. 
ANTUNES, H. A. et al. Algumas reflexões sobre uma base de métodos de programação linear multicritério Investigação Operacional, v. 9, n. 2, p. 19-35, 1989.

ANTUNES, H. A.; CLIMACO, J. N. An Integrated MOLP method base package - a guided tour of TOMMIX. Computers and Operations Research, v. 19, n. 7, p. 609-625, 1992. http://dx.doi.org/10.1016/0305-0548(92)90031-Y

ARROW, K. J. Social choice and individual values. London: John Wiley and Sons, 1963.

BOHORIS, G. A. A comparative assessment of some major quality awards. International Journal of Quality \& Reliability Management, v. 12, n. 9, p. 30-43, 1995. http://dx.doi.org/10.1108/02656719510101178

BRANS, J. P.; MARESCHAL, B.; VINCKE, P. Promethee: A New Family Of Outranking Methods In Multicriteria Analysis. In: INTERNATIONAL CONFERENCE OF OPERATIONAL RESEARCH, 10., 1984, Washington. Proceedings... Washington: North-Holland, 1984. p. 477-490.

CAUCHICK MIGUEL, P. A. Comparing the Brazilian national quality award with some of the major prizes. The TQM Magazine, v. 13, n. 4, 2001. http://dx.doi. org/10.1108/09544780110391675

CHANGKONG, Y.; HAIMES, Y. Multiobjective Decision Making. Amsterdam: Ed. North Holland, 1983. 235 p.

COSTA, H. G. An multicriteria approach to evaluate consumer satisfaction: a contribution to marketing. In: INTERNATIONAL CONFERENCE ON DECISION SUPPORT SYSTEMS - ISDSS'05, 8., 2005, Porto Alegre. Proceedings... Porto Alegre: International Society of Decision Suppotrt Systems, 2005. 10 p.

COSTA, H. G.; FREITAS, A. L. P. Metodologia multicritério para a medição e classificação do grau de satisfação de clientes. Metrologia 2000. São Paulo: Sociedade Brasileira de Metrologia, 2000.

COSTA, H. G.; HERRERA, W. D. M. Contribuições da análise multicritério à determinação do grau de proximidade em arranjos físicos. Produto \& Produção, v. 6, n. 1, p. 1-10, 2003.

COSTA, H. G. et al. ELECTRE TRl applied to costumers satisfaction evaluation. Produção, v. 17, n. 2, p. 230-245, 2007. http:// dx.doi.org/10.1590/S0103-65132007000200002

COSTA, H. G.; SOARES, A. C.; OLIVEIRA, P. F. Avaliação de transportadoras de materiais perigosos utilizando o método electre tri. Gestão \& Produção, v. 11, n. 4 , p. 221-229, 2004a.

COSTA, H. G.; SOARES, A. C.; OLIVEIRA, P. F. D. The electre tri method applied to the evaluation of companies transporting hazardous materials. Gestão \& Produção, v. 11, n. 2, 2004b. http://dx.doi.org/10.1590/S0104530X2004000200008

EUROPEAN FOUNDATION FOR QUALITY MANAGEMENT - EFQM. The EFQM Excellence Model. EFQM, 2008. Disponível em: <http://www.efqm.org/en/ tabid/132/default.aspx>. Acesso em: 08 out. 2009.

FlGUEIRA, J. R. et al. Electre Tri-C, a multiple criteria decision aiding sorting model applied to assisted reproduction. International Journal of Medical Informatics, v. 80, n. 4, p. 262-273, 2011. http://dx.doi.org/10.1016/j. ijmedinf.2010.12.001

FISHBURN, P. C. Utility theory for decision making. New York: Wiley, 1970. xiv, 234 p. (Operations Research Society of America Publications in operations research).
FISHBURN, P. C. Les mathématiques de la décision. Paris: Mouton, 1973. 102 p. (Mathématiques et sciences de l'homme,).

FREITAS, A. L. P.; COSTA, H. G. Uma abordagem multicritério para avaliação e classificação de serviços. Gestão \& Produção, v. 5, n. 3, p. 272 -283, 1998. http://dx.doi. org/10.1590/S0104-530X1998000300008

FREITAS, A. L. P.; COSTA, H. G. Development and Testing of a Multi-Criteria Approach to the Assessment of Service Quality: An Empirical Study in Brazil. International Journal of Management, v. 29, n. 2, Part 2, p. 18, 2012.

FREITAS, A. L. P.; RODRIGUES, S. G.; COSTA, H. G. Emprego de uma abordagem multicritério para classificação do desempenho de instituições de ensino superior. Ensaio: Avaliação e Políticas Públicas em Educação, v. 17, n. 65, p. 656-674, 2009. http://dx.doi.org/10.1590/S010440362009000400006

FUNDAÇÃO NACIONAL DA QUALIDADE - FNQ. Cadernos de Excelência: introdução ao modelo de excelência da gestão. FNQ, 2008. Disponível em: <http://www.fnq.org. br/pdf/CadernosExcelencia2008_00_introducao.pdf>. Acesso em: 03 set. 2009.

FUNDAÇÃO NACIONAL DA QUALIDADE - FNQ. Critérios de excelência:Avaliação e diagnóstico da gestão organizacional. FNQ, 2009. Disponivel em: <http://www.fnq.org.br/ Portals/_FNQ/Documents/web_CriteriosExcelencia2009_ mais_recente.pdf>. Acesso em: 21 ago. 2009.

GHOBADIAN, A.; WOO, H. S. Characteristics, benefits and shortcomings of four major quality awards. . International Journal of Quality \& Reliability Management, v. 13, n. 2, 1996.http://dx.doi.org/10.1108/02656719610109999

KEENEY, R. L.; RAIFFA, H. Decisions with Multiple Objectives: preferences and value tradeoffs. New York: John Willey \& Sons, 1976. 569 p.

LIKERT, R. A. Technique for measurement of attitudes. Archives of Psychology, v. 140, n. 1, p. 5-55, 1932.

LUIZ, N. M.; COSTA, A. F. D.; COSTA, H. G. Influência da graduação em engenharia de produção no perfil dos seus egressos: percepções discentes Students' perceptions of the influence of a degree in industrial engineering on their performance. Avaliação (Campinas), v. 15, n. 1, p. 101-120, 2010. http://dx.doi.org/10.1590/S141440772010000100006

MAVROIDIS, V.; TOLIOPOULOU, S.; AGORITSAS, C. A comparative analysis and review of national quality awards in Europe: Development of critical success factors". The TQM Magazine, v. 19, n. 5, 2007. http:// dx.doi.org/10.1108/09544780710817874

MILLER, G. A. The Magical Number Seven, Plus or Minus Two: Some Limits on Our Capacity for Processing Information. Psychological Review, v. 101, n. 2, p. 343-352, 1954. http://dx.doi.org/10.1037/0033-295X.101.2.343

MIRANDA, C. M. G. D.; ALMEIDA, A. T. D. Avaliação de pós-graduação com método ELECTRE TRI: o caso de engenharias 111 da capes. Produção, v. 13, p. 101-112, 2003. http://dx.doi.org/10.1590/S010365132003000300009

MOUSSEAU, V.; SLOWINSKI, R.; ZIELNIEWICZ, P. ELECTRE TRI 2.0a. methodological guide and user's manual. Paris: Université de Paris-Dauphine, 1999. Document du LAMSADE.

NEPOMUCENO, L. D. 0.; COSTA, H. G.; SHIMODA, E. Impact of professional master's programs on graduate students: 
Intercomparison of perceptions of students, faculty members, coordinators, and companies involved. Gestão \& Produção, v. 17, n. 4, p. 817-828, 2010. http://dx.doi. org/10.1590/S0104-530X2010000400014

NATIONAL INSITTUTE OSF STANDARDS AND TECHNOLOGY - NIST. Malcolm Baldrige National Quality Award. NIST, 2010. Disponível em: <http://www.nist. gov/baldrige/enter/index.cfm>. Acesso em: 05 fev. 2012.

NEVES, R. B.; COSTA, H. G. Avaliação de programas de pósgraduação: proposta baseada na integração ELECTRE TRI, SWOT e sistema CAPES. Revista Eletrônica Sistemas \& Gestão, v. 1, n. 3, p. 276-298, 2006.

POLITIS, Y.; SISKOS, Y. Multicriteria methodology for the evaluation of a Greek engineering department. European Journal of Operational Research, v. 156, n. 1, p. 223-240, 2004. http://dx.doi.org/10.1016/S03772217(02)00902-5

ROY, B. Classement et choix en presence de points de vue multiples (la methode ELECTRE). Lausanne Presses Polytechiniques et Universitaires Romandes, 1968.

ROY, B. ELECTRE 111: Un alghoritme de methode de classements fonde sur une representatio floue des preferences em presence de criteres multiples. Cahieres de CERO, v. 20, n. 1, p. 3-24, 1978.

ROY, B.; BERTIER, P. M. La methode ELECTRE Il: Une methode de classement en presence de criteres multiples. Paris: SEMA (Metra International), 1971. p. 45.

ROY, B.; BOYSSOU, D. Mèthodologie Multicritère d'Äide à la Décision. Paris Ed. Economica, 1985.

ROY, B.; HUGONNARD, J. C. Classement des prolongements de lignes de stations en banlieu parisienne. Paris: Université Dauphine et RATP, 1981. Cahiers u LAMSADE.

ROY, B.; SKALKA, J. M. ELECTRE IS: Aspécts methodologiques et guide d'utilization. Paris: Université de ParisDauphine, 1985. Cahier du LAMSADE.

SAATY, T. L. The Analytic Hierarquic Process. Pittsburg: RWS Publications, 1980.

SHAHROUDI, K.; KOHAN, N. Z. Verifying the relationship between sub-criterion in EFQM business model. Australian Journal of Basic and Applied Sciences, v. 5, n. 8, p. 417-428, 2011.
SHARMA, A. K.; TALWAR, B. Evolution of "Universal Business Excellence Model" incorporating Vedic philosophy. Measuring Business Excellence, v. 11, n. 3, p. 4-20, 2007. http://dx.doi.org/10.1108/13683040710820719

SZAJUBOK, N. K.; ALENCAR, L. H.; ALMEIDA, A. T. D. Modelo de gerenciamento de materiais na construção civil utilizando avaliação multicritério. Produção, v. 16, p. 303-318, 2006. http://dx.doi.org/10.1590/S010365132006000200010

SZAJUBOK, N. K.; MOTA, C. M. D. M.; ALMEIDA, A. T. D. Uso do método multicritério ELECTRE TRI para classificação de estoques na construção civil. Pesquisa Operacional, v. 26, p. 625-648, 2006.

TALWAR, B. Comparative study of core values of excellence models vis-à-vis human values. Measuring Business Excellence, v. 13, n. 4, p. 34-46, 2009. http://dx.doi. org/10.1108/13683040911006774

TALWAR, B. Business excellence models and the path ahead. TQM Journal, v. 23, n. 1, p. 21-35, 2011. http://dx.doi. $\operatorname{org} / 10.1108 / 17542731111097461$

TAVANA, M. et al. An EFQM-Rembrandt excellence model based on the theory of displaced ideal. Benchmarking, v. 18, n. 5, p. 644-667, 2011. http://dx.doi. org/10.1108/14635771111166802

VILAS BOAS, G. A. R.; COSTA, H. G. Modelagem para suporte à gestão organizacional: experimentação em uma indútria do segmento de malharia. Produção, v. 23, n. 2, p. 297-311, 2013. http://dx.doi.org/10.1590/S010365132012005000070

VINCKE, P. L'aide Multicritère à la Decision. Bruxelles: Editions de l'Université de Bruxelles - Editions Ellipses, 1989. 179 p.

YOUSEFIE, S.; MOHAMMADI, M.; MONFARED, J. H. Selection effective management tools on setting European Foundation for Quality Management (EFQM) model by a quality function deployment (QFD) approach. Expert Systems with Applications, v. 38, n. 8, p. 9633-9647, 2011. http://dx.doi.org/10.1016/j.eswa.2011.01.166

YU, W. ELECTRE TRI - Aspects Methodologiques et Guide d'Utilisation. Paris: Université de Paris-Dauphine, 1992. Document du LAMSADE.

ZELENY, M. Multiple Criteria Decision Making. New York: McGraw-Hil, 1982. p.

\title{
Multicriteria model for the evaluation and classification of organizational management: proposal and case
}

\begin{abstract}
This paper aims to present a multicriteria model for evaluating and classifying organizational performance with respect to the best practices in management. The proposed multicriteria model is based on the ELECTRE TRI method for obtaining degrees of credibility and ratings of organizational performance. An experimental study was conducted to investigate the application of the proposed model. Rating scales, based on Likert (1932), were used and a set of criteria was inspired by the following awards for management excellence: the Deming Prize, the Malcolm Baldridge Award, the National Quality Award and European Quality Award. As a result, it was possible to obtain a classification and to identify the criteria of excellence that should be prioritized to improve the classification achieved by an organization.
\end{abstract}

Keywords

Total quality. Multicriteria. Awards for excellence. Decision ELECTRE TRI. 